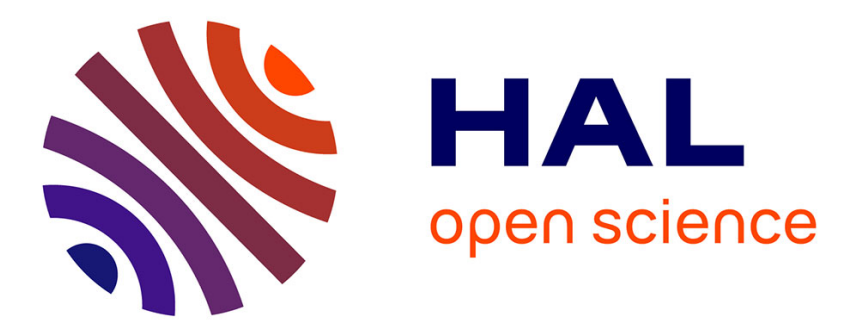

\title{
Socioeconomic Position and Incidence of Acute Myocardial Infarction: a Meta-Analysis
}

Edison Manrique-Garcia, Anna Sidorchuk, Johan Hallqvist, Tahereh Moradi

\section{To cite this version:}

Edison Manrique-Garcia, Anna Sidorchuk, Johan Hallqvist, Tahereh Moradi. Socioeconomic Position and Incidence of Acute Myocardial Infarction: a Meta-Analysis. Journal of Epidemiology and Community Health, 2010, 65 (4), pp.301. 10.1136/jech.2009.104075 . hal-00576250

\section{HAL Id: hal-00576250 \\ https://hal.science/hal-00576250}

Submitted on 14 Mar 2011

HAL is a multi-disciplinary open access archive for the deposit and dissemination of scientific research documents, whether they are published or not. The documents may come from teaching and research institutions in France or abroad, or from public or private research centers.
L'archive ouverte pluridisciplinaire HAL, est destinée au dépôt et à la diffusion de documents scientifiques de niveau recherche, publiés ou non, émanant des établissements d'enseignement et de recherche français ou étrangers, des laboratoires publics ou privés. 
1 Socioeconomic Position and Incidence of Acute Myocardial Infarction: a Meta-Analysis

2 Edison Manrique-Garcia $^{\mathrm{a} *}$, Anna Sidorchuk $^{\mathrm{abc} *}$, Johan Hallqvist $^{\mathrm{ad}}$, Tahereh Moradi $^{\mathrm{b}}$

$3 \quad *$ Both authors contributed equally

$4{ }^{\mathrm{a}}$ Department of Public Health Sciences, Division of Social Medicine, Karolinska Institutet,

5 Stockholm, Sweden

$6{ }^{\mathrm{b}}$ Institute of Environmental Medicine, Division of Epidemiology, Karolinska Institutet,

7 Stockholm, Sweden

$8{ }^{\mathrm{c}}$ St. Petersburg State Medical Academy named after II. Mechnicov, Division of

9 Epidemiology, St. Petersburg, Russia

$10{ }^{\mathrm{d}}$ Department of Public Health and Caring Sciences, Uppsala University, Uppsala, Sweden

11 Correspondence to: Anna Sidorchuk, MD, PhD

12

13
Karolinska Institutet

Department of Public Health Sciences, Division of Social Medicine Norrbacka, Karolinska Hospital

SE-171 76, STOCKHOLM, SWEDEN

E-mail: Anna.Sidorchuk@ki.se

Phone: +46-524 80014, Fax: +46- 8-30 8008

Key Words: Acute Myocardial Infarction, socioeconomic position, meta-analysis. 


\section{ABSTRACT:}

22 Background: Negative socioeconomic gradient is established for coronary heart disease

23 (CHD) mortality and survival, while socioeconomic pattering of disease incidence is less

24 investigated. To study socioeconomic inequalities in incidence of acute myocardial infarction

25 (AMI), the major component of CHD, we undertook meta-analysis to summarize existing

26 evidence on the issue. Methods: A systematic search was performed in PubMed and

27 EMBASE databases for observational studies on AMI incidence and socioeconomic position

28 (SEP), published in English through April 2009. Random-effects model was used to pool the

29 risks estimates from the individual studies. Results: Among 1,181 references, 70 studies

30 fulfilled inclusion criteria. An overall increased risk of AMI among the lowest SEP was

31 found for all three indicators: income (pooled RR=1.71, 95\% CI 1.43 to 2.05), occupation

32 (pooled $\mathrm{RR}=1.35,95 \% \mathrm{CI} 1.19$ to 1.53 ) and education (pooled $\mathrm{RR}=1.34,95 \% \mathrm{CI} 1.22$ to

33 1.47). The strongest associations were seen in high-income countries such us US/Canada and

34 Europe, while the results were inconsistent for middle- and low-income regions. Conclusion:

35 AMI incidence is associated with low SEP. The nature of social stratification at the level of

36 economic development of a country could be involved in the differences of risk of AMI

37 between social groups. 
Acute Myocardial Infarction (AMI) is a major cause of death and disability

worldwide.[1] According to an estimate from the WHO, about $40 \%$ of all deaths will be

42 related to cardiovascular diseases (CVD) in 2020, with AMI being the main single cause.[2]

43 Projection of global mortality and burden of disease for 2030 presented that despite the

44 decline in mortality due to coronary heart disease (CHD) in high-income countries during the

45 last decades, it will remain the leading cause of mortality in low-and middle-income

46 countries.[3-5] Due to high mortality rate, severe damage to physical and mental health, long

47 rehabilitation periods and a high rate of disability, the burden of AMI is a highly significant

48 social issue.[6]

49 There is a considerable body of evidence linking socioeconomic position (SEP) with

50 the conventional risk factors for CHD, including AMI as the major component of CHD.[7-9]

51 Lower SEP is often associated with health-damaging lifestyle resulting in the development of

52 poor dietary habits as well as influencing behaviours related to smoking and physical

53 activity.[10] Individuals with low SEP are prone to be exposed to multiple risk factors and,

54 therefore, seem to suffer dramatically from excess burden of disease.[11]

55 Associations between SEP and CVD mortality and survival have been well discussed in 56 a number of reviews.[12-16] However, quantitative assessment of socioeconomic pattering of

57 CVD incidence and AMI incidence is presented to a lower extent. Use of incidence data

58 generally avoids problems with post-diagnosis SEP changes as well as with different survival

59 by socioeconomic groups.[17] Addressing the issue of social inequality in AMI further, it is

60 important to estimate the individual contribution of each SEP indicator rather than

61 interchangeable SEP measures as they affect health through different pathways and causal

62 mechanisms.[18] We undertook meta-analysis as a quantitative approach to summarize the 
63 existing evidence on the issue $[19,20]$ to investigate the association between AMI incidence

64 and various SEP measures including educational attainment, income, and occupation

65 categories.

66

67

68 SUBJECTS AND METHODS

69 Search strategy

70 To identify eligible studies of associations between socioeconomic determinants and AMI

71 incidence, we conducted a systematic search in PubMed and EMBASE databases for articles

72 published in English-speaking, peer-reviewed journals from 1966 to April 01, 2009. For this

73 search, we used the relevant medical subject heading (MeSH) terms and key words related to

74 socioeconomic determinants combined with specific outcome defined as "acute myocardial

75 infarction". The details of electronic search are reported on-line in Appendix 1. The

76 reference lists were scrutinized to identify additional studies.

78 Study selection

79 To be included in this meta-analysis, studies had to 1) use original data; 2) be designed as

80 case-control or cohort studies; 3) consider AMI incidence as an outcome; 4) present risk

81 estimates with $95 \%$ confidence intervals (CIs) on the association between incident cases of

82 AMI and at least one measure of SEP, or report sufficient information to compute these for

83 men, women or both.

84 The articles were selected for inclusion if the study event was originally defined as AMI

85 either nonfatal or in combination with fatal or reported as a composite outcome of AMI and 
86 death attributed to CHD / ischemic heart disease (IHD), including sudden death. We also

87 considered studies where the outcome definition composed AMI with congestive heart

88 failure [21, 22] or unstable angina (UA).[23] In order to avoid the inclusion of chronic

89 ischemic disease, we did not include studies if the outcome of interest was presented as CHD

90 event corresponding to codes 410-414 in ICD-9 or I21-I25 in ICD-10 with no further

91 specification. Neither did we include studies if AMI was combined with angina pectoris,

92 coronary atherosclerosis or stroke with no possibility to extract data on AMI alone. We

93 sought data on the first AMI event to assess the impact of social inequality on development of

94 the disease in people apparently free from acute ischemic disease. Studies focusing

95 exclusively on mortality and survival were not included.

96 SEP indicators were included only if they were based on income, educational

97 attainment or occupational categories. Studies utilizing a social indicator constructed as a

98 combination of two or more standard socioeconomic indicators were not included. Neither

99 did we include studies where the SEP measure was based on ownership of car/houses/health

100 insurance or presented as categories of deprivation. Only the studies with adult individual-

101 level measure of SEP were included. No restrictions were made by the type of SEP, personal

102 or household.

103 When overlap was identified from various studies, the original data were included only

104 once, prioritizing datasets providing maximally-adjusted risk estimates. If not, we used the

105 most up-to-date information or studies with greater number of participants. Two co-authors

106 (EM, AS) independently extracted relevant studies following the inclusion criteria. In case of

107 missing data we contacted the corresponding authors. All authors[24-29] from whom the

108 additional information was requested provided us with data we asked for. Discrepancies were

109 resolved by consensus in a panel meeting (TM, EM, AS). 
111 Data extraction

112 The following information was extracted from each publication: the first author's last

113 name, the year of publication, the country where the study was performed, study design,

114 years of data collection and type of controls (population-based / hospital-based) in case-

115 control studies, duration of follow-up in cohort studies, the sample size, indicators of SEP,

116 source and type of SEP data, definition and status of the outcome, status of event, sex and age

117 along with the risk estimates for AMI associated with SEP with corresponding 95\% CIs, and

118 the variables controlled for. The information on country where the study was performed was

119 then classified both according to the geographical area (US/Canada, Europe, Asia, Latin

120 America, Middle East) and country's income level (high-, middle-, or low-income

121 countries).[5] From each study, we extracted the risk estimate both minimally-and

122 maximally-adjusted for the potential confounders. Unless otherwise stated, we included in the

123 analysis the maximally-adjusted estimates in order to overcome inconsistency in handling

124 confounding and mediating variables. We considered the study risk estimates to be

125 minimally-adjusted if unadjusted or adjusted for age, sex and residence, either one or all, by

126 matching, restriction, stratification or statistical adjustment, and to be maximally-adjusted if

127 in addition adjusted for any of the classical well-recognised AMI-specific risk factors. If the

128 original study reported risk estimates in association with more than one measure of SEP, each

129 estimate was extracted and then analysed as its own association with the specific SEP.

\section{Statistical analysis}


Relative risk (RR) was used as the measure for summary statistic of associations

between SEP and AMI incidence. To simplify the procedure, RRs represented all reported study-specific results derived from cohort studies and odds ratios (ORs) from case-control studies.[30] Due to the initial assumption of between-study heterogeneity, a random-effects model of DerSimonian-Laird,[31] which incorporates both within- and between-study variability, was applied to combine log RRs across the studies. To augment comparability between the studies using different SEP categories, we compared the lowest versus the highest SEP category. If the original study reported the risk estimates not in this order, we back-calculated the point estimate and $95 \%$ CIs. For the articles that did not report estimates in form of RRs or ORs, the risk estimates and 95\% CIs were recalculated from the presented raw data by using standard equations. If the original study reported separate RRs for different sexes[32-37] or different races[34] or if RRs were reported separately for two subcohorts with rheumatoid arthritis and non-inflammatory rheumatoid disorders within same cohort,[38] the risk estimates were pooled (weighted by inverse of their variance) to obtain a single estimate per SEP from each study.

To evaluate the statistical heterogeneity among studies we used the Cochran's $Q$ test.[39] This test examines the null hypothesis that heterogeneity across the study estimates of RRs is due to chance by using a chi-square test with degrees of freedom equal to the number of studies minus one. For $Q$ statistic we considered $\mathrm{P}<0.1$ as a representative of statistically significant heterogeneity. To describe the proportion of total variance in study estimates explained by heterogeneity between study variation rather than chance, we calculated the $I^{2}$ statistic.[40]

Random-effect meta-regression analyses were performed to identify study-level factors contributing to heterogeneity between studies. The explanatory variables included study 
design, geographical area, country's income level, publication year (before 2000 / 2000 and after), type of adjustment with respect to AMI-specific risk factors, type of controls in casecontrol studies, personal or household SEP, and status of the event and the natural logarithm of RR was the dependent variable.[41-43] An univariate meta-regression was performed for each study-level factors for studies on income, education and occupation. A backward stepwise approach was used to select the significant variables to be included in a multivariate analysis. In addition, a series of subgroup analyses were conducted by stratifying the original studies by sex, country's income level and geographical region, study design, adjustment strategy, publication period, personal or household SEP and type of study event. The stability of the results was also evaluated in leave-one-out sensitivity analysis in which the influence of the individual study on the overall pooled RR was estimated by omitting one study at a time.[44]

We assessed publication bias by constructing funnel plots and using the Egger's regression asymmetry test and the Begg-Mazumdar adjusted rank correlation test.[45, 46]. All statistical analyses were performed using STATA version 10 (StataCorp, College Station, TX). $P$-values that were less than 0.05 were considered statistically significant. All statistical tests were two-sided.

\section{RESULTS}

\section{Study characteristics}

Total search in the electronic databases revealed 2,539 references and among those 1,358 were overlapping between different search categories. The search strategy for the 1,181 unique references is presented on Figure 1 as the QUOROM statement[47] flowchart where 
the detailed procedure of the reference identification along with the information on exclusion criteria applied on different stages of the selection is described. Briefly, 855 articles did not address the issue of interest and were excluded after the screening the abstracts leaving us with 326 full-text articles for further examination. Of these, only 64 articles fulfilled the predefined inclusion criteria and were selected to be included in the analysis. The reference lists of the selected articles were scrutinized and 19 articles were additionally identified fulfilling the inclusion criteria. To mitigate overlapping in study populations, several studies being initially considered relevant for the analysis[24, 26, 48-63] were excluded and substituted by more recent ones, providing maximally-adjusted risk estimates or with greater number of participants [18, 23, 33, 35, 64-71].

Two risk estimates for educational attainment and AMI incidence presented by Chang $\mathrm{C}$ et al.[66] for women from Eastern Europe and whose from non-European countries (Latin America, Asia and Africa) were independently included in the analysis, referred as Chang C (A) and Chang C (B), respectively. Similar to that, two substudies on occupational SEP and AMI described in the article by Mattila K et al.[27] (series I and series II), were also analysed separately. The same strategy was applied to data derived from the articles by Eaker E et al.[72] and Qureshi A et al.,[73] where occupational and educational SEP were presented among women at the age of 45-54 years (Eaker E (A)) and 55-64 years (Eaker E (B)) and patients younger 50 years (Qureshi A (A)) and older 50 years (Qureshi A (B)), respectively. Substudies from the articles by Bosma $\mathrm{H}$ et al.[74] originated from Lithuania (Bosma $\mathrm{H}$ (A)) and The Netherlands (Bosma H(B)) were included independently. Therefore, 70 original studies from 65 articles, extending back to the year 1968, were finally included in the analysis. 
In total, there were 37 case-control studies in 35 articles[23, 25, 27, 28, 32, 33, 35,

203 65-67, 75-99] reporting associations with different SEP among 74,056 AMI cases and

204619,652 controls and 33 cohort studies, including 2 studies nested in cohort, in 30 articles[18,

$20521,29,34,36-38,64,68-74,100-114]$ where association with SEP was studied for 28,629

206 incident cases among 3,869,270 participants. Supplementary table S1 presents data on

207 detailed study characteristics of the included studies.

208

209 Overall result

210 The overall results of this meta-analysis provided evidence of a significant increase in

211 risk of AMI among the lowest socioeconomic categories for all three socioeconomic

212 indicators (Fig. 2-4). Heterogeneity was observed for all three SEP indicators $(\mathrm{p}<0.001)$

213 (Table1).

214 
Table 1 Pooled estimates for the lowest versus the highest socioeconomic category and incidence of acute myocardial infarction in series of subgroup analyses

\begin{tabular}{|c|c|c|c|c|c|c|c|c|c|}
\hline \multirow[t]{3}{*}{ Subgroup analysis } & \multicolumn{9}{|c|}{$\mathrm{n}=$ Number of studies, Pooled RR $(95 \% \mathrm{CI})$, p-value for $Q$ test for heterogeneity, $I^{2}$ statistic (\%) } \\
\hline & $\mathbf{n}$ & Income & $Q$ p-value & $\mathbf{n}$ & Education & $Q$ p-value & $\mathbf{n}$ & Occupation & $Q$ p-value \\
\hline & & & $I^{2}(\%)$ & & & $I^{2}(\%)$ & & & $I^{2}(\%)$ \\
\hline \multirow[t]{2}{*}{ Summary pooled } & 19 & $1.71(1.43$ to 2.05$)$ & $<0.001$ & 47 & $1.34(1.22$ to 1.47$)$ & $<0.001$ & 33 & $1.35(1.19$ to 1.53$)$ & $<0.001$ \\
\hline & & & 95.9 & & & 77.6 & & & 81.6 \\
\hline \multicolumn{10}{|l|}{ Sex } \\
\hline \multirow[t]{2}{*}{ Male } & 7 & 1.50 (1.31 to 1.72$)$ & 0.039 & 13 & $1.24(1.04$ to 1.48$)$ & $<0.001$ & 18 & 1.34 (1.16 to 1.55$)$ & $<0.001$ \\
\hline & & & 54.8 & & & 83.7 & & & 77.3 \\
\hline Female & 4 & 1.87 (1.48 to 2.36$)$ & 0.015 & 15 & $1.58(1.25$ to 2.00$)$ & $<0.001$ & 11 & 1.87 (1.34 to 2.60$)$ & $<0.001$ \\
\hline
\end{tabular}




\section{Country's income}

group

High

$15 \quad 1.76$ (1.46 to 2.12$)$

$<0.001$

96.3

Middle or Low

4

$4 \quad 1.46(0.60$ to 3.54$) \quad<0.001$

81.3

13

1.16

$6(0.97$

.97 to 1.39$)$

54

$<0.001$

$30 \quad 1.41(1.25$ to 1.59$)$

$<0.001$

79.3

80.6

Geographical region ${ }^{a}$

US/Canada

$4 \quad 1.49(1.27$ to 1.75$) \quad 0.350$

$10 \quad 1.42(1.28$ to 1.57$)$

0.340

6

$1.44(1.22$ to 1.70$)$

0.988

9.2

10.6

0.0

Europe $^{\mathrm{b}}$

$11 \quad 1.80(1.46$ to 2.21$) \quad<0.001$

$29 \quad 1.33$ (1.17 to 1.50$)$

$<0.001$

26

1.37 (1.19 to 1.58$)$

$<0.001$ 


\begin{tabular}{|c|c|c|c|c|c|c|c|c|c|}
\hline & & & 97.0 & & & 82.6 & & & 84.4 \\
\hline \multirow[t]{2}{*}{ Asia } & 3 & $1.52(0.29$ to 7.93$)$ & $<0.001$ & 3 & $1.90(0.48$ to 7.58$)$ & 0.001 & 1 & $0.67(0.41$ to 1.09$)$ & - \\
\hline & & & 88.0 & & & 86.3 & & & \\
\hline \multirow[t]{2}{*}{ Latin America } & 1 & 1.27 (1.06 to 1.52$)$ & - & 3 & 1.23 (1.03 to 1.47$)$ & 0.086 & 0 & - & \\
\hline & & & & & & 59.2 & & & \\
\hline Middle East & 0 & - & & 1 & $1.18(0.27$ to 5.15$)$ & - & 0 & - & \\
\hline \multicolumn{10}{|l|}{ Adjustment strategy $^{c}$} \\
\hline Unadjusted for AMI & 10 & 1.79 (1.44 to 2.24$)$ & $<0.001$ & 29 & $1.37(1.21$ to 1.56$)$ & $<0.001$ & 19 & $1.27(1.05$ to 1.54$)$ & $<0.001$ \\
\hline risk factors ${ }^{\mathrm{d}}$ & & & 97.5 & & & 81.3 & & & 68.1 \\
\hline Adjusted for AMI & 9 & $1.58(1.20$ to 2.08$)$ & 0.001 & 16 & $1.26(1.06$ to 1.49$)$ & $<0.001$ & 14 & $1.41(1.19$ to 1.68$)$ & $<0.001$ \\
\hline risk factors ${ }^{\mathrm{e}}$ & & & 70.1 & & & 68.4 & & & 80.5 \\
\hline
\end{tabular}


Design

\begin{tabular}{|c|c|c|c|c|c|c|c|c|c|}
\hline \multirow[t]{2}{*}{ Cohort $^{\mathrm{f}}$} & 10 & $1.59(1.45$ to 1.75$)$ & 0.016 & 23 & $1.45(1.27$ to 1.66$)$ & $<0.001$ & 19 & $1.39(1.24$ to 1.56$)$ & 0.002 \\
\hline & & & 55.8 & & & 78.7 & & & 55.0 \\
\hline \multirow[t]{2}{*}{ Case-control } & 9 & 1.91 (1.37 to 2.66$)$ & $<0.001$ & 24 & $1.23(1.07$ to 1.41$)$ & $<0.001$ & 14 & $1.17(0.88$ to 1.55$)$ & $<0.001$ \\
\hline & & & 91.3 & & & 74.1 & & & 82.8 \\
\hline
\end{tabular}

Type of control for

case-control studies

Population $^{\mathrm{g}}$

6

2.36 (1.86 to 2.99$)$

0.005

69.9

31.05 (0.41 to 2.69$)$

0.003
82.8

82.8

$12 \quad 1.41(1.20$ to 1.66$)$

$<0.001$

11

77.0

80.5

Hospital
0.001

3

0.84 (0.61 to 1.17$)$

0.296

65.2

17.8 
Publication period

\begin{tabular}{|c|c|c|c|c|c|c|c|c|c|}
\hline \multirow[t]{2}{*}{ Before 2000} & 6 & 2.64 (2.16 to 3.22$)$ & 0.738 & 15 & 1.43 (1.12 to 1.82$)$ & $<0.001$ & 16 & 1.34 (1.02 to 1.76$)$ & 0.005 \\
\hline & & & 0.0 & & & 70.7 & & & 54.6 \\
\hline \multirow[t]{2}{*}{2000 or after } & 13 & $1.58(1.29$ to 1.93$)$ & $<0.001$ & 32 & $1.31(1.18$ to 1.45$)$ & $<0.001$ & 17 & 1.37 (1.18 to 1.59$)$ & $<0.001$ \\
\hline & & & 97.2 & & & 80.2 & & & 87.9 \\
\hline
\end{tabular}

Personal or household

SEP

Personal

$13 \quad 1.84$ (1.49 to 2.26$)$

$<0.001$

Household $^{\mathrm{h}}$
$6 \quad 1.45$ (1.00 to 2.08$)$

\section{4}

$<0.001$

89.0

$\begin{array}{llll}<0.001 & 31 & 1.36(1.20 \text { to } 1.55) & <0.001 \\ 77.6 & & & 81.0 \\ & & & \\ & 2 & 1.35(0.35 \text { to } 5.18) & 0.002\end{array}$

89.1 
Event $^{\mathrm{c}}$

Clearly first event

ever

Potentially first event $^{\mathrm{i}}$

$$
15 \quad 1.59(1.30 \text { to } 1.94)
$$

$<0.001$ 38

${ }^{a}$ Data from Chang C et al [66] are not included due to presenting combined results from Latin American and Asian countries

${ }^{\mathrm{b}}$ Corresponds to data from both Western European and Eastern European countries

${ }^{\mathrm{c}}$ On this item data from the study by Qureshi A et al. [73] are not available

${ }^{\mathrm{d}}$ Unadjusted or adjusted for age, sex and residence only (either one or all)

${ }^{\mathrm{e}}$ Adjusted for at least one AMI-specific risk factors such as smoking, diabetes, hypertension, hypercholesterolemia, physical activity and BMI

${ }^{\mathrm{f}}$ Corresponds to cohort studies and case-control studies nested in cohort

${ }^{\mathrm{g}}$ Corresponds to either population-based controls or relatives/neighbourhood controls

${ }^{\text {h }}$ Corresponds to the family income SEP or husband's occupation for women or combination of women's and husband's occupation SEP 
i Corresponds to the studies where less than $<10 \%$ of cases may had had a prior AMI as well as the studies where information on cases' history on AMI was not clarified by the authors 
The strongest pattern was seen for the lowest income group where the incidence of AMI increased by $71 \%$ compared to high income group ( $\mathrm{RR}=1.71,95 \%$ CI 1.43 to 2.05 ) (Table 1$)$.

244 Further stratification by sex, adjustment strategy, study design, status of event, personal or

245 household type of SEP or publication years did not alter the overall pooled results. No association was seen for the case-control studies utilizing hospital controls, while studies with population controls revealed statistically significant association between the lowest income group and AMI (Table 1).

We observed a 34\% increased risk of AMI for the lowest educational group ( $R R=1.34$, 95\% CI 1.22 to 1.47 ) (Table 1). The increase was apparent in subanalyses after stratifying by the main study characteristics, i.e. sex, adjustment strategy, study design, publication period, and status of event, apart from for the case-control studies with hospital controls (Table 1).

Increased incidence of AMI was observed when studies on occupational categories were pooled ( $\mathrm{RR}=1.35,95 \%$ CI 1.19 to 1.53 ) (Table 1). The increase persisted for the lowest occupational SEP when pooling studies within subgroups with different sex, status of event, and publication years. Non-significant increase was seen in subanalysis for household SEP measure (husband's occupation for women). The results were less consistent among casecontrol studies (Table 1). occupational SEP in high-income countries and in regional areas such us US/Canada and Europe (Table 1). No significant associations were, however, apparent between any of the SEP determinants and AMI incidence in studies carried out in the middle-or low income countries, particularly in Asian region. In contrary, for middle-or low income countries an inverse association was observed for the results combined across the studies on occupational 265 SEP. 
There was a substantial heterogeneity in overall result among the studies on all SEP

determinants $(p<0.001)$ that remained significant for the results from most of the

subanalyses. However, no or low heterogeneity was present when analyses were restricted to

studies originated from US/Canada. There was a low heterogeneity among studies on

occupation when results were combined for middle-or low-income countries. Similar pattern

was seen when studies on income published before the year 2000 were analysed separately.

In random-effect meta-regression analyses the relation between SEP and AMI

incidence persisted irrespective to the design of original studies, though in case-control

studies multivariate regression indicated the association between type of control (hospital vs.

population controls) and RR of AMI for studies on all SEP indicators (for income $B$

coefficient $(\beta)=-2.76,95 \% \mathrm{CI}-4.77$ to $-0.76, \mathrm{p}=0.007$; for education $\beta=-0.40,95 \% \mathrm{CI}$ -

0.75 to $-0.05, \mathrm{p}=0.02$; for occupation $\beta=-0.51,95 \% \mathrm{CI}-1.00$ to $-0.02, \mathrm{p}=0.04)$. Pooling

together the cohort studies and case-control studies with population controls only had no

effect on the overall results (pooled RR for income $=1.80,95 \%$ CI 1.50 to 2.16; pooled RR

for education $=1.43,95 \% \mathrm{CI} 1.30$ to 1.58 ; pooled $\mathrm{RR}$ for occupation $=1.41,95 \% \mathrm{CI} 1.24$ to

1.60). Type of AMI event (potentially first vs. clearly first event ever) was significantly

associated with outcome in multivariate regression analyses in studies on income $(\beta=0.24$,

$95 \% \mathrm{CI} 0.04$ to $0.46, \mathrm{p}=0.02)$ and occupation $(\beta=0.54,95 \% \mathrm{CI} 0.27$ to $0.82, \mathrm{p}<0.001)$.

Among other study-level factors only two revealed associations with the outcome. For studies

on income SEP the publication period (published in year 2000 and after vs. published before year 2000) reached statistical significance in univariate, but not in multivariate metaregression analysis (data not shown). For occupational SEP in multivariate analysis country's income group (middle-or low-income countries vs. high-income countries) was associated with RR of AMI $(\beta=-1.24,95 \%$ CI -1.74 to $-0.74, p<0.001)$. No other study-level 
characteristics for any of studied SEP indicators were found significant in meta-regression analyses.

No publication bias were observed for educational SEP (Egger's test $\mathrm{p}=0.49$ ) with borderline significant result for occupational SEP $(\mathrm{p}=0.05)$, while selection of the studies focusing on income introduced publication bias $(\mathrm{p}=0.03)$. The publication bias funnel plots are presented as Supplementary material (Figure S1). No individual studies significantly altered the overall estimates based on the results of the sensitivity analysis.

\section{DISCUSSION}

Our results indicated an increased incidence of myocardial infarction among the lowest socioeconomic categories in income (71\%), education (34\%) and occupation (32\%) compared to the highest category of the corresponding SEP. The associations were significant for both males and females and consistent for most of the results from the subgroup analyses. The increased risk of AMI for the lowest categories of all SEP indicators was most evident in high-income countries, while middle-or low-income countries revealed less consistent associations probably due to a limited number of the studies included in the latter strata.

SEP is a surrogate measure for numerous factors that may affect health. There is an increasing awareness that SEP indicators should not be used interchangeably because they may represent different risk factors [115] and relate to different causal pathways.[18, 116] Recent reviews discussed the new approach for health researchers to study the socioeconomic inequalities in health by measuring the respective impact of separate socioeconomic indicators on health outcomes along with the mediating mechanisms and adjustment suggested by each indicator rather than studying an effect of a single composite SEP 
variable. $[18,117,118]$ In our analysis the attempt was made to identify the independent contribution of each SEP indicator to AMI outcome across regions and over time. The results must be interpreted with cautions because of the observational nature of the data.[19, 119, 120]

Several methodological issues are needed to be taken under consideration. One of the limitations in our study was possible differences in the definition and classification of SEP across studies. It was of particular importance for educational and income SEP categories since differences in countries' general economy, educational systems and cultural issues could cause the variability in the scales used to classify the exposure. The methodological limitations for quantitative comparison of studies on SEP due to the substantial dissimilarity in exposure measures used in different studies over time and geographical regions have been discussed previously.[115] Lack of uniformity in reporting SEP data in original studies have limited our ability to investigate a social gradient in AMI incidence. To reduce the inconsistency in SEP stratification across the original studies and to obtain the meaningful indicator of socioeconomic inequality in health, it has been suggested to measure the difference between the extreme categories of SEP, i.e. to compare the highest and the lowest SEP strata.[117, 118, 121] Studies selected for our analysis varied significantly in presenting SEP categories that prevented us from collapsing the middle-level SEP categories in one. To overcome the problem and to increase the comparability across the studies, we applied the suggested approach and compared the extreme categories that, however, impaired the possibility of studying the social gradient and could be considered as a limitation of the analysis.

Due to significant heterogeneity observed across the selected studies, the pooled results should be interpreted with cautions. The nature of observational studies introduces design- 
related heterogeneity that basically reflects the disparity in the study characteristics.[122] In our case the heterogeneity was probably boosted by the initial unevenness in study bases as well as in outcome definitions and status of event used in the original studies along with inconsistency in measures of exposure and variability in handling confounding and mediating factors. The incidental manner of reporting SEP data in descriptive tables in a numerous studies, resulted in using estimates adjusted neither by matching nor by statistical adjustment and, probably influenced the completeness of the search. The result-related heterogeneity[122] may be less pronounced in our meta-analysis due to non-substantial variability between the original point estimates and considerable overlaps of the confidence intervals. Meta-regression analyses indicated type of study controls in case-control studies as potential sources of heterogeneity between studies for all SEP indicators. Several metaanalyses discussed the limitations introduced by pooling the results of studies different in study design or type of control groups as in hospital-based case-control studies the choice of controls may affect the representativeness of exposure.[115, 123] In addition, characteristics of hospital catchment area and presence of Berkson's bias, if study exposure is related to the risk of being hospitalized for the control diseases, may jeopardize comparability of studies selected for the analysis even further.[124] Socioeconomic inequalities may influence all above mentioned conditions and, thus, be one of the reasons for type of controls to be a source of heterogeneity. For income-based SEP overall results for studies published before 2000 yielded highly significant association with the outcome along with no heterogeneity between studies, though in multivariable meta-regression the publication year was not recognised as a potential source for heterogeneity. We must, however, acknowledge that in meta-analysis of observational studies the results of multivariable meta-regression can also be confounded by unidentified study-level factors.[41] 
Publication bias is a concern in meta-analysis since it might lead to overestimation of the relative risk. Since our meta-analysis was restricted to English-speaking peer reviewed publications, our estimates may have been affected by missing data from the studies performed in the low-or middle-income countries where SEP may be differently associated with AMI. It may explain the presences of publication bias detected in our analysis for combined estimates for studies on income-based SEP. In our study, publication bias may be partially explained by variability in outcome definitions and SEP measures or if studies with relatively smaller sample size and inconsistent results were lacking in the analysis representing significance bias, size bias and suppression publication bias.[119] resulted in a limited number of studies. We acknowledge the fact that numerous studies potentially relevant for the analysis were, however, excluded if AMI was reported as a study deliberately narrowed the analysis to AMI only.

Another restraint deals with the variety of confounders and/or mediators across the original studies. It might mainly be crucial for the pooled results if the adjustment strategy behavioural and lifestyle factors.[125-128] Therefore, the choice of variables in the original 
402

403

404 intermediate steps in the causal pathways will result in underestimation of the relation between SEP and the disease, while relation will be overstated if genuine confounders left unadjusted. Evidence from the recent studies and reviews indicate that different SEP measures can simultaneously be included in the multivariable models as they do not act as proxy for each other,[117, 118, 129-131] while biological, behavioural and psychological factors can mediate an association between SEP and AMI.[126-128, 131] To reduce the influence of various adjustment we, therefore, performed separate subanalyses for studies minimally-and maximally-adjusted that in our analysis yielded the similar results.

Our findings presented the overall increase in risk of AMI incidence among the lowest SEP that has previously been reported for AMI mortality and CHD morbidity.[13, 16]

The aforementioned results corroborated the strong evidence of the relation between socioeconomic deprivation and incidence of acute ischemic events. Further research providing validated information is required to address public health strategies to reduce the risk of AMI among the most vulnerable groups in different countries and among different societies. It is imperative to emphasise the importance of such studies, particularly for the regions with lower level of economic development, where the epidemic of CHD is becoming a public health issue.

Source of financial support: Meta-analysis was supported by grant from the Swedish Council for Working Life and Social Research [FAS, 2006-0230 to Tahereh Moradi]. The study founder had no role in the design, collection, analysis, or interpretation of the data, or in the writing or decision to submit the manuscript.

Competing of interest: None declared. 
behalf of all authors and does grant on behalf of all authors, an exclusive licence (or nonEpidemiology and Community Health and any other BMJPGL products to exploit all subsidiary rights, as set out in our licence.

\section{What is already known?}

Adverse socioeconomic position is related to coronary heart disease mortality and survival.

\section{What does this study add?}

This meta-analysis reveals an association between low socioeconomic position (SEP) and increased incidence of acute myocardial infarction (AMI). The associations were consistent for both men and women.

People from the lowest strata of income-based SEP have a $71 \%$ greater risk to develop myocardial infarction compared to those in the highest strata. An increased risk in AMI incidence of $34 \%$ and $35 \%$ was found for the lowest compared to the highest categories of educational and occupational SEP, respectively.

The socioeconomic patterns in myocardial infarction incidence were seen to be most pronounced for high-income countries. The nature of social stratification at the level of economic development of a country could be involved in the differences of risk of AMI between social groups. 


\section{Policy Implications}

Public health policies aiming at reducing the risk of AMI should address socioeconomic position both in the promotion and the evaluation of preventive measures.

The potential for variation in the strength of AMI inequalities between different societies should be acknowledged by national and international policy makers. 


\section{REFERENCES}

418 1. Thygesen, K, Alpert JS, White HD. Universal definition of myocardial infarction. $J$ $419 \quad$ Am Coll Cardiol 2007;50(22):2173-95.

420 2. Murray C, Lopez A. Alternative vision of the future: Projecting Mortality and 421 Disability, 1990-2020. In: Murray C, Lopez A, eds. The global burden of disease: a 422 comprehensive assessment of mortality and disability from disease, injuries and risk 423 factors in 1990 and projected to 2020. Cambridge, Mass:Harvard School of Public $424 \quad$ Health 1996:325-95.

425 3. Okrainec K, Banerjee DK, Eisenberg MJ. Coronary artery disease in the developing $426 \quad$ world. Am Heart J 2004;148(1):7-15.

427 4. Pais PS. Early intervention and prevention of myocardial infarction. J Hypertens $428 \quad$ Suppl 2006;24(2):S25-30.

429 5. Mathers CD, Loncar D. Projections of global mortality and burden of disease from $430 \quad 2002$ to 2030. PLoS Med 2006;3(11):e442.

431 6. Hoit BD, Giplin EA, Henning H, et al. Myocardial infarction in young patients: an $432 \quad$ analysis by age subsets. Circulation 1986;74(4):712-21.

$4337 . \quad$ Levenson JW, Skerrett PJ, Gaziano JM. Reducing the global burden of 434 cardiovascular disease: the role of risk factors. Prev Cardiol 2002;5(4):188-99.

435 8. Tyroler HA. The influence of socioeconomic factors on cardiovascular disease risk 436 factor development. Prev Med 1999;29(6 Pt 2):S36-40.

437 9. Lynch J, Davey Smith G, Harper S. Explaining the social gradient in coronary heart 438 disease: comparing relative and absolute risk approaches. J Epidemiol Community 439 Health 2006;60(5):436-41. 
440 10. Kaplan GA, Keil JE. Socioeconomic factors and cardiovascular disease: a review of the literature. Circulation 1993;88(4 Pt 1):1973-98.

11. Ruberman W, Weinblatt E, Goldberg JD, et al. Psychosocial influences on mortality after myocardial infarction. N Engl J Med 1984;311(9):552-9.

12. Krantz DS, McCeney MK. Effects of psychological and social factors on organic disease: a critical assessment of research on coronary heart disease. Annu Rev Psychol 2002;53:341-69.

13. Gonzalez MA, Rodriguez Artalejo F, Calero JR. Relationship between socioeconomic status and ischaemic heart disease in cohort and case-control studies: 1960-1993. Int J Epidemiol 1998;27(3):350-8.

14. Brezinka V, Kittel F. Psychosocial factors of coronary heart disease in women: a review. Soc Sci Med 1996;42(10):1351-65.

15. Strike PC, Steptoe A. Psychosocial factors in the development of coronary artery disease. Prog Cardiovasc Dis 2004;46(4):337-47.

16. Alboni P, Amadei A, Scarfo S, et al. In industrialized nations, a low socioeconomic status represents an independent predictor of mortality in patients with acute myocardial infarction. Ital Heart J 2003;4(8):551-8.

17. Devesa SS, Diamond EL. Socioeconomic and racial differences in lung cancer incidence. Am J Epidemiol 1983:118(6):818-31.

18. Geyer S, Hemstrom O, Peter P, et al. Education, income, and occupational class cannot be used interchangeably in social epidemiology. Empirical evidence against a common practice. J Epidemiol Community Health 2006;60(9):804-10.

19. Stroup DF, Berlin JA, Morton SC, et al. Meta-analysis of observational studies in epidemiology: a proposal for reporting. Meta-analysis Of Observational Studies in Epidemiology (MOOSE) group. JAMA 2000;283(15):2008-12. 
465 20. Zwahlen M, Renehan A, Egger M. Meta-analysis in medical research: potentials and limitations. Urol Oncol 2008;26(3):320-9.

21. Bosma H, Van Jaarsveld CHM, Tuinstra J, et al. Low control beliefs, classical coronary risk factors, and socio-economic differences in heart disease in older persons. Soc Sci Med 2005;60(4):737-45.

22. Pell J, Pell A, Morrison C, et al. Retrospective study of influence of deprivation on uptake of cardiac rehabilitation. BMJ 1996;313(7052):267-8.

23. Kontogianni MD, Panagiotakos DB, Chrysohoou C, et al. The impact of olive oil consumption pattern on the risk of acute coronary syndromes: The CARDIO2000 case-control study. Clin Cardiol 2007;30(3):125-9.

24. Ahlbom A, Feychting M, Gustavsson A, et al. Occupational magnetic field exposure and myocardial infarction incidence. Epidemiology 2004;15(4):403-8.

25. Falger PR, Schouten EG. Exhaustion, psychological stressors in the work environment, and acute myocardial infarction in adult men. $J$ Psychosom Res 1992;36(8):777-86.

26. Hallqvist J, Lynch J, Bartley M, et al. Can we disentangle life course processes of accumulation, critical period and social mobility? An analysis of disadvantaged socioeconomic positions and myocardial infarction in the Stockholm Heart Epidemiology Program. Soc Sci Med 2004;58(8):1555-62.

27. Mattila KJ, Nieminen MS, Valtonen VV, et al. Association between dental health and acute myocardial infarction. BMJ 1989;298(6676):779-81.

28. Pais P, Pogue J, Gerstein H, et al. Risk factors for acute myocardial infarction in Indians: a case-control study. Lancet 1996;348(9024):358-63. 
29. Vogels EA, Lagro-Janssen AL, van Weel C. Sex differences in cardiovascular disease: are women with low socioeconomic status at high risk? Br J Gen Pract 1999;49(449):963-6.

30. Greenland S. Quantitative methods in the review of epidemiologic literature. Epidemiol Rev 1987;9:1-30.

31. DerSimonian R, Laird N. Meta-analysis in clinical trials. Control Clin Trials 1986;7(3):177-88.

32. Baigi A, Holmen A, Hogstedt B, et al. Birthplace and social characteristics as risk factors for acute myocardial infarction in the province of Halland, Sweden. Public Health 2002;116(5):279-84.

33. Ciruzzi M, Pramparo P, Rozosnik J, et al. Diabetes and risk of acute myocardial infarction. CVD Prevention 2000;3(1):40-6.

34. Diez Roux, AV, Stein Merkin S, Arnett D, et al. Neighborhood of residence and incidence of coronary heart disease. N Engl J Med 2001;345(2):99-106.

35. Ljung R, Hallqvist J. Accumulation of adverse socioeconomic position over the entire life course and the risk of myocardial infarction among men and women: results from the Stockholm Heart Epidemiology Program (SHEEP). J Epidemiol Community Health 2006;60(12):1080-4.

36. Rayce SL, Christensen U, Hougaard C, et al. Economic consequences of incident disease: the effect on loss of annual income. Scand J Public Health 2008;36(3):25864.

37. Salomaa V, Niemela M, Miettinen H, et al. Relationship of socioeconomic status to the incidence and prehospital, 28-day, and 1-year mortality rates of acute coronary events in the FINMONICA myocardial infarction register study. Circulation 2000;101(16):1913-8. 
513 38. Wolfe F, Michaud K. The risk of myocardial infarction and pharmacologic and nonpharmacologic myocardial infarction predictors in rheumatoid arthritis: A cohort and nested case-control analysis. Arthritis and Rheumatism 2008;58(9):2612-21.

39. Cochran WG. The combination of estimates from different experiments. Biometrics 1954;8:101-29.

40. Higgins JP, Thompson SG, Deeks JJ, et al. Measuring inconsistency in meta-analyses. BMJ 2003;327(7414):557-60.

41. Baker WL, Michel White C, Cappelleri JC, et al. Understanding heterogeneity in meta-analysis: the role of meta-regression. Int J Clin Pract 2009;63(10):1426-34.

42. Thompson SG, Sharp SJ. Explaining heterogeneity in meta-analysis: a comparison of methods. Stat Med 1999;18(20): 2693-708.

43. van Houwelingen HC, Arends LR, Stijnen T. Advanced methods in meta-analysis: multivariate approach and meta-regression. Stat Med 2002;21(4):589-624.

44. Tobias A. Assessing the influence of a single study in meta-analysis. Stata Tech Bull $1999 ; 47: 15-7$.

45. Begg CB, MazumdarM. Operating characteristics of a rank correlation test for publication bias. Biometrics 1994;50(4):1088-101.

46. Egger M, Davey Smith G, Schneider M, et al. Bias in meta-analysis detected by a simple, graphical test. BMJ 1997;315(7109):629-34.

47. Moher D, Cook DJ, Eastwood S, et al. Improving the quality of reports of metaanalyses of randomised controlled trials: the QUOROM statement. Quality of Reporting of Meta-analyses. Lancet 1999;354(9193):1896-900.

48. Andersen I, Burr H, Kristensen TS, et al. Do factors in the psychosocial work environment mediate the effect of socioeconomic position on the risk of myocardial 
infarction? Study from the Copenhagen Centre for Prospective Population Studies. Occup Environ Med 2004;61(11):886-92.

49. Appels A, Falger PR, Schouten EG Vital exhaustion as risk indicator for myocardial infarction in women. J Psychosom Res 1993;37(8):881-90.

50. Bobak M, Hertzman C, Skodova Z, et al. Association between psychosocial factors at work and nonfatal myocardial infarction in a population-based case-control study in Czech men. Epidemiology 1998;9(1):43-7.

51. Chang CL, Marmot M, Fareley T, et al. The influence of economic development on the association between education and the risk of acute myocardial infarction and stroke. J Clin Epidemiol 2002;55(8):741-7.

52. Ciruzzi M, Pramparo P, Esteban O, et al. Case-control study of passive smoking at home and risk of acute myocardial infarction. J Am Coll Cardiol 1998;31(4):797-803.

53. Ciruzzi M, Pramparo P, Rozlosnik J, et al. Hypertension and the risk of acute myocardial infarction in Argentina. Prev Cardiol 2001;4(2):57-64.

54. Ciruzzi M, Schargorodsky H, Rozlosnik J, et al. Frequency of family history of acute myocardial infarction in patients with acute myocardial infarction. Am J Cardiol 1997;80(2):122-7.

55. Gustavsson P, Plato N, Hallquist J, et al. A population-based case-referent study of myocardial infarction and occupational exposure to motor exhaust, other combustion products, organic solvents, lead, and dynamite. Epidemiology 2001;12(2):222-8.

56. Hallqvist J, Moller J, Ahlbom A, et al. Does heavy physical exertion trigger myocardial infarction? A case-crossover analysis nested in a population-based casereferent study. Am J Epidemiol 2000;151(5):459-67. 
57. Nyboe J, Jensen G, Appleyard M, et al. Risk factors for acute myocardial infarction in Copenhagen. I: Hereditary, educational and socioeconomic factors. Copenhagen City Heart Study. Eur Heart J 1989;10(10):910-6.

58. Panagiotakos DB, Pitsavos C, Chrysohoou C, et al. Risk stratification of coronary heart disease in Greece: final results from the CARDIO2000 Epidemiological Study. Prev Med 2002;35(6):548-56.

59. Peter R, Gassler H, Geyer S. Socioeconomic status, status inconsistency and risk of ischaemic heart disease: a prospective study among members of a statutory health insurance company. J Epidemiol Community Health 2007;61(7):605-11.

60. Rosengren A, Wedel H, Wilhelmsen L. Coronary heart disease and mortality in middle aged men from different occupational classes in Sweden. BMJ 1988;297(6662):1497-500.

61. Rosenlund M, Berglind N, Gustavsson A, et al. Environmental tobacco smoke and myocardial infarction among never-smokers in the Stockholm Heart Epidemiology Program (SHEEP). Epidemiology 2001;12(5):558-64.

62. Van Lenthe FJ, Gevers E, Joung I, et al. Material and behavioral factors in the explanation of educational differences in incidence of acute myocardial infarction: the Globe study. Ann Epidemiol 2002;12(8):535-42.

63. Weinehall L, Johnson O, Jahsson J-H, et al. Perceived health modifies the effect of biomedical risk factors in the prediction of acute myocardial infarction. An incident case-control study from northern Sweden. J Intern Med 1998;243(2):99-107.

64. Andersen I, Gamborg M, Osler M, et al. Income as mediator of the effect of occupation on the risk of myocardial infarction: does the income measurement matter? J Epidemiol Community Health 2005;59(12):1080-5. 
65. Bobak M, Hertzman C, Marmot M. Own education, current conditions, parental material circumstances, and risk of myocardial infarction in a former communist country. J Epidemiol Community Health 2000;54(2):91-6.

66. Chang CL, Shipley MJ, Marmot MG, et al. Can cardiovascular risk factors explain the association between education and cardiovascular disease in young women? J Clin Epidemiol 2002;55(8):749-55.

67. Collijn DH, Appels A, Nijhuis F. Psychosocial risk factors for cardiovascular disease in women: the role of social support. Int J Behav Med 1995;2(3):219-32.

68. Hippe M, Vestbo J, Hein HO, et al. Familial predisposition and susceptibility to the effect of other risk factors for myocardial infarction. J Epidemiol Community Health 1999;53(5):269-76.

69. Huisman M, Van Lenthe F, Avendano M, et al. The contribution of job characteristics to socioeconomic inequalities in incidence of myocardial infarction. Soc Sci Med 2008;66(11):2240-52.

70. Schaufelberger M, Rosengren A. Heart failure in different occupational classes in Sweden. Eur Heart J 2007;28(2):212-8.

71. Wennberg P, Lindahl B, Hallmans G, et al. The effects of commuting activity and occupational and leisure time physical activity on risk of myocardial infarction. Eur J Cardiovasc Prev Rehabil 2006;13(6):924-30.

72. Eaker ED, Pinsky J, Castelli WP. Myocardial infarction and coronary death among women: psychosocial predictors from a 20-year follow-up of women in the Framingham Study. Am J Epidemiol 1992;135(8):854-64.

73. Qureshi AI, Suri M, Saad M, et al. Educational attainment and risk of stroke and myocardial infarction. Med Sci Monit, 2003;9(11):CR466-73. 
608 74. Bosma H, Appels A, Sturmans F, et al. Educational level of spouses and risk of mortality: the WHO Kaunas-Rotterdam Intervention Study (KRIS). Int J Epidemiol

610 1995;24(1):119-26.

611

75. Alfredsson L, Karasek R, Theorell T. Myocardial infarction risk and psychosocial work environment: an analysis of the male Swedish working force. Soc Sci Med 1982;16(4):463-7.

76. Altieri A, Tavani A, Gallus S, et al. Occupational and leisure time physical activity and the risk of nonfatal acute myocardial infarction in Italy. Ann Epidemiol 2004;14(7):461-66.

77. Burr ML, Sweetnam PM. Family size and paternal unemployment in relation to myocardial infarction. J Epidemiol Community Health 1980;34(2):93-5.

78. Danesh J, Youngman L, Clark S, et al. Helicobacter pylori infection and early onset myocardial infarction: case-control and sibling pairs study. $B M J$ 1999;319(7218):1157-62.

79. Hebert PR, Buring JE; O'Connor GT, et al. Occupation and risk of nonfatal myocardial infarction. Arch Intern Med 1992;152(11):2253-7.

80. Ising H, Babisch W, Gunther T. Work noise as a risk factor in myocardial infarction. J Clin Basic Cardiol 1999;2(1):64-8.

81. Ismail J, Jafar TH, Jafary FH, et al. Risk factors for non-fatal myocardial infarction in young South Asian adults. Heart 2004;90(3):259-63.

82. Janszky I, Ahlbom A, Hallquist J, et al. Hospitalization for depression is associated with an increased risk for myocardial infarction not explained by lifestyle, lipids, coagulation, and inflammation: the SHEEP Study. Biol Psychiatry 2007;62(1):25-32. 
631 83. Kabagambe EK, Baylin A, Ruiz-Navares E, et al. Decreased consumption of dried

632 mature beans is positively associated with urbanization and nonfatal acute myocardial 633 infarction. J Nutr 2005;135(7):1770-5.

634 84. Kono S, Handa K, Kawano T, et al. Alcohol intake and nonfatal acute myocardial 635 infarction in Japan. Am J Cardiol 1991;68(10):1011-4.

636 85. Lind E, Theorell T. Sociological characteristics and myocardial infarctions. $J$ 637 Psychosom Res 1973;17(1):59-73.

86. Lovasi GS, Vernez Moudon A, Smith NL, et al. Evaluating options for measurement of neighborhood socioeconomic context: evidence from a myocardial infarction casecontrol study. Health Place 2008;14(3):453-67.

87. Malinauskiene V, Grazuleviciene R, Azaraviciene A. Socioeconomic differences in myocardial infarction risk among 35-64 year old women in Kaunas, Lithuania. Przegl Lek 2003;60 Suppl 6:86-8.

88. Malinauskiene V, Grazuleviciene R, Nieuwenhuijsen MJ, et al. Myocardial infarction risk and occupational categories in Kaunas 25-64 year old men. Occup Environ Med 2002;59(11):745-50.

89. Malinauskiene V, Theorell T, Grazuleviciene R, et al. Low job control and myocardial infarction risk in the occupational categories of Kaunas men, Lithuania. $J$ Epidemiol Community Health 2004;58(2):131-5.

90. Martinez-Gonzalez MA, Fernandez-Jarne E, Serrano-Martinez M, et al. Mediterranean diet and reduction in the risk of a first acute myocardial infarction: an operational healthy dietary score. Eur J Nutr 2002;41(4):153-60.

91. Netterstrom B, Nielsen FE, Kristensen TS, et al. Relation between job strain and myocardial infarction: a case-control study. Occup Environ Med 1999;56(5):339-42. 
655 92. Ostlin P, Klerdal K, Hammar N. Time trends in incidence of myocardial infarction in

656 male and female dominated occupations in Stockholm, Sweden. Scand J Public

657 Health 2008;36(5):546-54.

658 93. Patil SS, Joshi R, Gupta G, et al. Risk factors for acute myocardial infarction in a rural 659 population of central India: a hospital-based case-control study. Natl Med J India $660 \quad 2004 ; 17(4): 189-94$.

661 94. Piegas LS, Avezum A, Pereira JCR, et al. Risk factors for myocardial infarction in 662 663 Brazil. Am Heart J 2003;146(2):331-8.

95. Rosenlund M, Bellander T, Nordquist T, et al. Traffic-generated air pollution and myocardial infarction. Epidemiology 2009;20(2):265-71.

96. Sarraf-Zadegan N, Amiri M, Maghsoudloo S. Helicobacter pylori relation to acute myocardial infarction in an Iranian sample. Coronary Health Care 2001;5(4):202-7.

97. Wardwell WI, Hyman M, Bahnson CB. Socio-environmental antecedents to coronary heart disease in 87 white males. Soc Sci Med 1968;2(2):165-83.

98. Wielgosz AT, Wielgosz M, Biro E, et al. Risk factors for myocardial infarction: the importance of relaxation. Br J Med Psychol 1988;61 ( Pt 3):209-17.

99. Vitullo F, Marchioli R, Di Mascio R, et al. Family history and socioeconomic factors as predictors of myocardial infarction, unstable angina and stroke in an Italian population. PROGETTO 3A Investigators. Eur J Epidemiol 1996;12(2):177-85.

100. Chaix B, Rosvall M, Merlo J. Neighborhood socioeconomic deprivation and residential instability: effects on incidence of ischemic heart disease and survival after myocardial infarction. Epidemiology 2007;18(1):104-11.

101. Croft P, Hannaford PC. Risk factors for acute myocardial infarction in women: evidence from the Royal College of General Practitioners' oral contraception study. BMJ 1989;298(6667):165-8. 
680 102. Engstrom G, Tyden P, Berglund G, et al. Incidence of myocardial infarction in

681

682

683 women. A cohort study of risk factors and modifiers of effect. J Epidemiol

Community Health 2000;54(2):104-7.

103. Hedblad B, Jonsson S, Nilsson P, et al. Obesity and myocardial infarction Vulnerability related to occupational level and marital status. A 23-year follow-up of an urban male Swedish population. J Intern Med, 2002;252(6):542-50.

104. Kuper H, Adami H-O, Theorell T, et al. Psychosocial determinants of coronary heart disease in middle-aged women: a prospective study in Sweden. Am J Epidemiol 2006;164(4):349-57.

105. Lang T, Ducimetiere P, Arveiler D, et al. Incidence, case fatality, risk factors of acute coronary heart disease and occupational categories in men aged 30-59 in France. Int J Epidemiol 1997;26(1):47-57.

106. Lapidus L, Bengtsson C. Socioeconomic factors and physical activity in relation to cardiovascular disease and death. A 12 year follow up of participants in a population study of women in Gothenburg, Sweden. Br Heart J 1986;55(3):295-301.

107. Lynch JW, Kaplan GA, Cohen RD, et al. Do cardiovascular risk factors explain the relation between socioeconomic status, risk of all-cause mortality, cardiovascular mortality, and acute myocardial infarction? Am J Epidemiol 1996;144(10):934-42.

108. Marmot MG, Shipley MJ, Hemingway H, et al. Biological and behavioural explanations of social inequalities in coronary heart disease: The Whitehall II study. Diabetologia 2008;51(11):1980-88.

109. Orth-Gomer K, RosengrenA, Wilhelmsen L. Lack of social support and incidence of coronary heart disease in middle-aged Swedish men. Psychosom Med 1993;55(1):3743. 
110. Rosvall M, Engstrom G, Hedblad B, et al. The role of preclinical atherosclerosis in the explanation of educational differences in incidence of coronary events. Atherosclerosis 2006;187(2):251-6.

111. Rosvall M, Gerward S, Engstrom G, et al. Income and short-term case fatality after myocardial infarction in the whole middle-aged population of Malmo, Sweden. Eur J Public Health 2008;18(5):533-8.

112. Shekelle RB, Ostfeld AM, Paul O. Social status and incidence of coronary heart disease. J Chronic Dis 1969;22(6):381-94.

113. Weikert C, Stefan N, Schulze M, et al. Plasma fetuin-A levels and the risk of myocardial infarction and ischemic stroke. Circulation 2008;118(24):2555-62.

114. Wolinsky FD, Wyrwich KW, Jung SC, et al. The risk of hospitalization for acute myocardial infarction among older adults. J Gerontol A Biol Sci Med Sc, 1999;54(5):M254-61.

115. Poole C, Greenland S, Luetters C, et al. Socioeconomic status and childhood leukaemia: a review. Int J Epidemiol 2006;35(2):370-84.

116. Lahelma E, Martikainen P, Laaksonen M, et al. Pathways between socioeconomic determinants of health. J Epidemiol Community Health 2004;58(4):327-32.

117. Braveman PA, Cubbin C, Egerter S, et al. Socioeconomic status in health research: one size does not fit all. JAMA 2005;294(22):2879-88.

118. Shavers VL. Measurement of socioeconomic status in health disparities research. $J$ Natl Med Assoc 2007;99(9):1013-23.

119. Greenland S, O'Rourke K. Meta-Analysis. In: Rothman K, ed. Modern Epidemiology. Lippincott Williams and Williams: Philadelphia, PA 2008: 652-83. 
120. Oreopoulos A, Padwal R, Norris CM, et al. Effect of obesity on short- and long-term mortality postcoronary revascularization: a meta-analysis. Obesity (Silver Spring) $2008 ; 16(2): 442-50$.

121. Conway DI, Petticrew M, Marlborough H, et al. Socioeconomic inequalities and oral cancer risk: a systematic review and meta-analysis of case-control studies. Int $J$ Cancer 2008;122(12):2811-9.

122. Engberg S. Systematic reviews and meta-analysis: studies of studies. J Wound Ostomy Continence Nurs 2008;35(3):258-65.

123. Key J, Hodson S, Omar RZ, et al. Meta-analysis of studies of alcohol and breast cancer with consideration of the methodological issues. Cancer Causes Control 2006;17(6):759-70.

124. Wacholder S, Silverman DT, McLaughlin JK, et al. Selection of controls in casecontrol studies. II. Types of controls. Am J Epidemiol 1992;135(9):1029-41.

125. Blair AS, Lloyd-Williams F, Mair FS. What do we know about socioeconomic status and congestive heart failure? A review of the literature. J Fam Pract 2002;51(2):169.

126. Kilander L, Berglund L, Boberg M, et al. Education, lifestyle factors and mortality from cardiovascular disease and cancer. A 25-year follow-up of Swedish 50-year-old men. Int J Epidemiol 2001;30(5):1119-26.

127. Steptoe A, Marmot M. The role of psychobiological pathways in socio-economic inequalities in cardiovascular disease risk. Eur Heart J 2002;23(1):13-25.

128. Suadicani P, Hein HO, Gyntelberg F. Strong mediators of social inequalities in risk of ischaemic heart disease: a six-year follow-up in the Copenhagen Male Study. Int J Epidemiol 1997;26(3):516-22.

129. Georgiades A, Janszky I, Blom M, et al. Financial strain predicts recurrent events among women with coronary artery disease. Int J Cardiol 2008;135:175-83. 
752 130. Pollack CE, Chideya S, Cubbin C, et al. Should health studies measure wealth? A

753

754

755

756

757

758 systematic review. Am J Prev Med 2007;33(3):250-64.

131. Wilkinson RG, Pickett KE. Income inequality and population health: a review and explanation of the evidence. Soc Sci Med 2006;62(7):1768-84. 
759

760

761

762

763

764 Figure 2. Relative Risk (RR) and 95\% confidence intervals (CIs) for acute myocardial

765

766

\section{FIGURE LEGENDS}

Figure 1. The QUOROM ${ }^{\mathrm{a}}$ statement [47] flowchart for study selection.

${ }^{a}$ Quality of Reports of Meta-Analyses of Randomised Controlled Trials infarction incidence and income categories (the lowest vs. the highest socioeconomic position category) in individual studies and for all studies combined. RRs from the individual studies are indicated by squares and the size of the squares represents the statistical weight that each study contributed to the random-effect summary estimate. Horizontal lines indicate the studyspecific 95\% CIs. Diamond represents the overall summary RR and its 95\% CIs.

Figure 3. Relative Risk (RR) and 95\% confidence intervals (CIs) for acute myocardial infarction incidence and educational attainment (the lowest vs. the highest socioeconomic position category) in individual studies and for all studies combined. RRs from the individual studies are indicated by squares and the size of the squares represents the statistical weight that each study contributed to the random-effect summary estimate. Horizontal lines indicate the study-specific 95\% CIs. Diamond represents the overall summary RR and its 95\% CIs.

Figure 4. Relative Risk (RR) and 95\% confidence intervals (CIs) for acute myocardial infarction incidence and occupational categories (the lowest vs. the highest socioeconomic position category) in individual studies and for all studies combined. RRs from the individual 
781 studies are indicated by squares and the size of the squares represents the statistical weight

782 that each study contributed to the random-effect summary estimate. Horizontal lines indicate

783 the study-specific 95\% CIs. Diamond represents the overall summary RR and its 95\% CIs. 


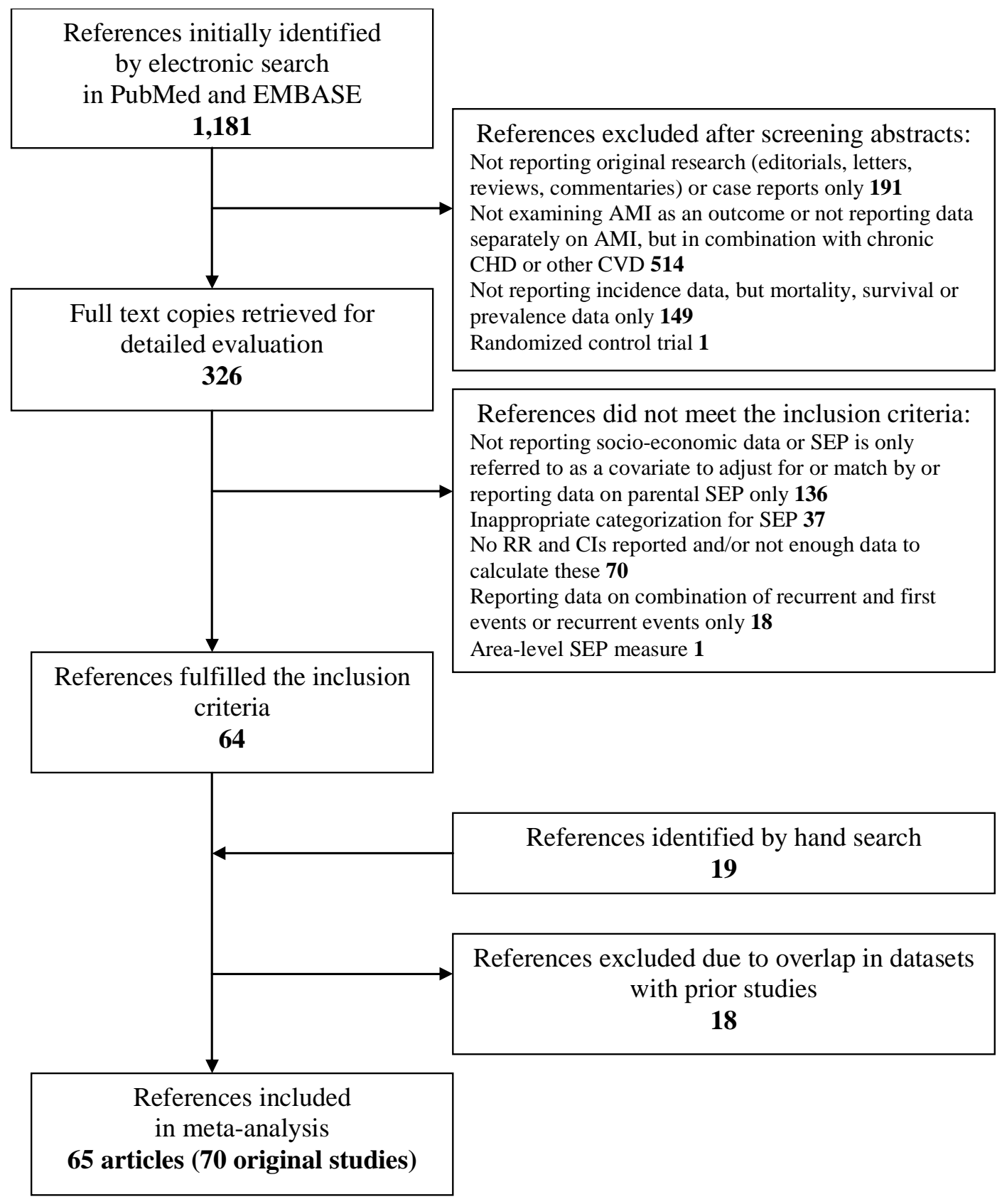


RR (95\% Cl)

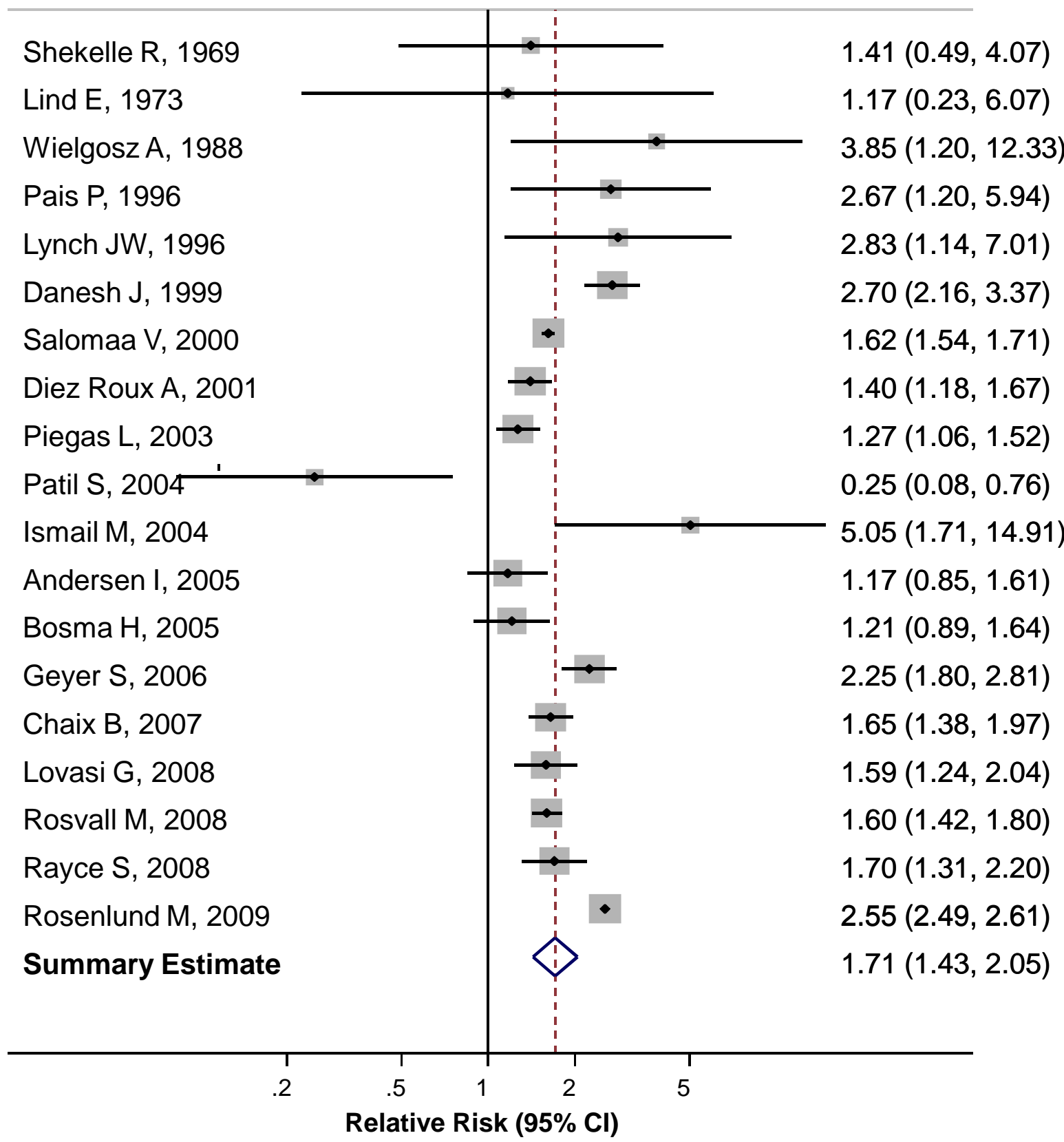




\section{First author, Publication Year}

\section{Shekelle R, 1969}

Alfredsson $L, 1982$

Lapidus L, 1986

Wielgosz A, 1988

Eaker E (A), 1992

Eaker E (B), 1992

Falger P, 1992

Collijn D, 1995

Bosma H (A), 1995

Bosma H (B), 1995

Vitullo $F, 1996$

Pais P, 1996

Hippe M, 1999

Wolinsky FD, 1999

Ising $\mathrm{H}, 1999$

Bobak M, 2000

Engstrom G, 2000

Salomaa V, 2000

Ciruzzi M, 2000

Diez Roux A, 2001

Sarraf-Zadegan N, 2001

Baigi A, 2002

Chang C (A), 2002

Chang C (B), 2002

Martinez-Gonzalez M, 2002

Malinauskiene V, 2002

Malinauskiene V, 2003

Qureshi A (A), 2003

Qureshi A (B), 2003

Piegas L, 2003

Patil S, 2004

Ismail M, 2004

Altieri A, 2004

Kabagambe E, 2005

Bosma H, 2005

Geyer S, 2006

Kuper H, 2006

Wennberg P, 2006

Rosvall M, 2006

Chaix B, 2007

Kontogianni M, 2007

Janszky I, 2007

Rayce S, 2008

Wolfe F, 2008

Huisman M, 2008

Lovasi G, 2008

Weikert C, 2008

Summary Estimate

\section{RR (95\% Cl)}

$3.01(0.35,25.54)$

$1.29(1.00,1.66)$

$10.70(1.15,99.96)$

$2.78(1.08,7.17)$

$2.32(0.78,6.91)$

$1.13(0.72,1.76)$

$3.71(1.36,10.15)$

$0.68(0.32,1.44)$

$1.15(0.61,2.18)$

$0.48(0.29,0.79)$

$1.05(0.51,2.15)$

$1.71(1.41,2.07)$

$1.40(1.11,1.77)$

$2.26(1.68,3.04)$

$1.67(0.87,3.21)$

$2.86(0.90,9.06)$

$1.51(1.44,1.58)$

$1.10(0.84,1.44)$

$1.54(1.25,1.90)$

$1.18(0.27,5.15)$

$1.57(1.32,1.86)$

$1.10(0.52,2.32)$

$1.00(0.47,2.12)$

$0.60(0.29,1.25)$

$0.94(0.68,1.29)$

$1.51(0.96,2.37)$

$1.70(1.20,2.40)$

$1.30(1.11,1.52)$

$1.49(1.20,1.85)$

$0.65(0.35,1.19)$

$25.00(4.23,147.83)$

$0.85(0.61,1.18)$

$3.49(1.84,6.62)$

$1.90(1.29,2.79)$

$1.85(1.27,2.70)$

$2.19(1.29,3.72)$

$1.43(1.24,1.65)$

$1.06(0.81,1.39)$

$1.53(1.34,1.75)$

$0.45(0.34,0.59)$

$1.24(0.53,2.91)$

$1.72(1.06,2.80)$

$1.29(1.05,1.58)$

$1.22(0.91,1.63)$

$1.34(1.22,1.47)$

Relative Risk (95\% Cl) 


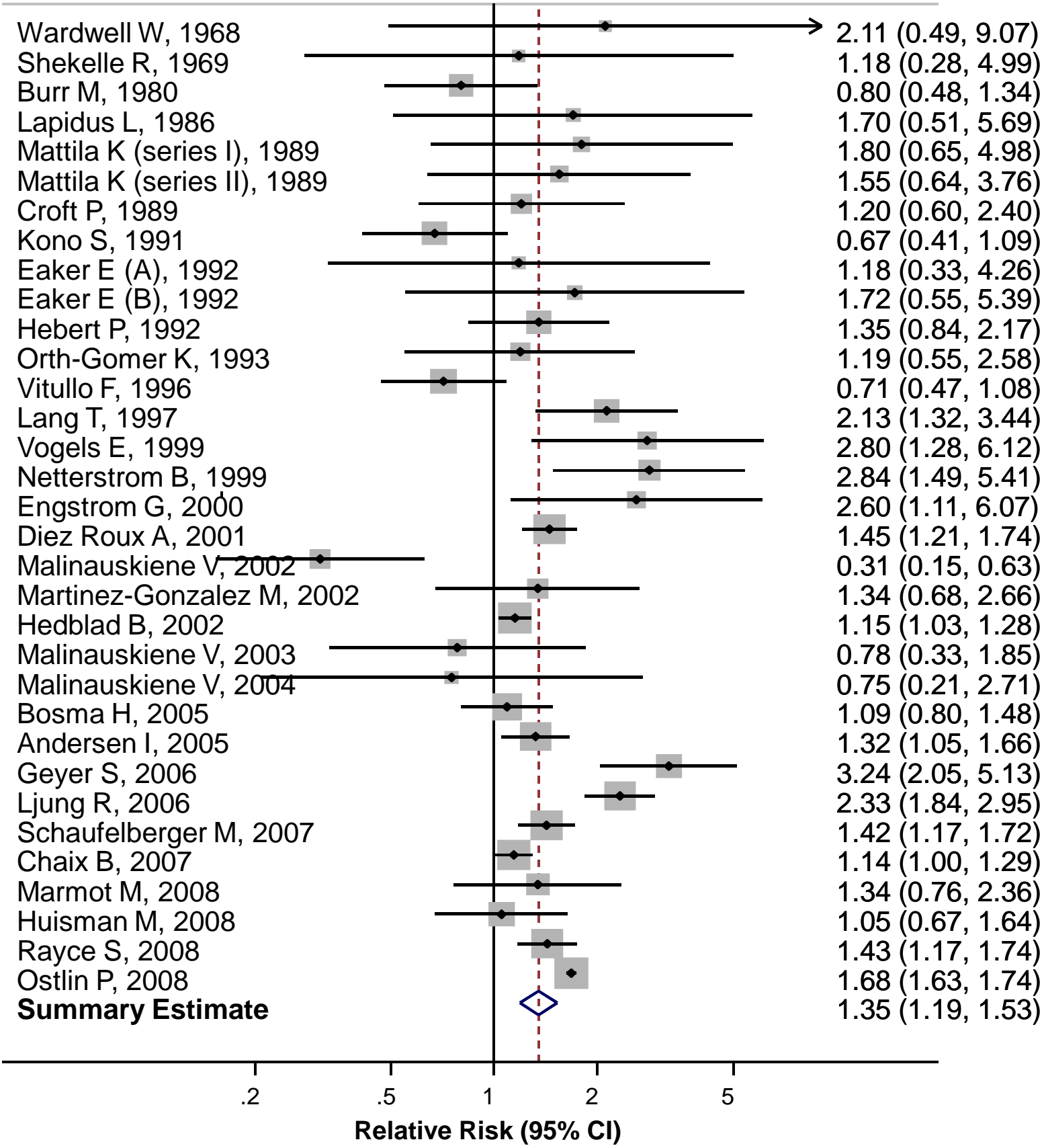

